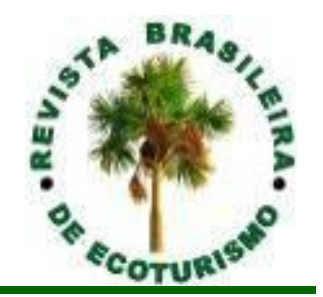

\title{
Indicadores de sustentabilidad turística: una aplicación metodológica para el destino Galápagos - Ecuador
}

\section{Tourism Sustainability Indicators: a methodological application for Galápagos destination - Ecuador}

\author{
Angelica Maria Saeteros, Edson Vicente da Silva, Diego Paul Viteri Nuñez
}

\begin{abstract}
RESUMEN: El turismo es una actividad económica considerada una excelente alternativa para el desarrollo de los destinos, sin embargo las actividades económicas son las que causan mayor impacto negativo al ambiente por lo que es necesario emprender acciones para promover el desarrollo sustentable de los destinos. Los indicadores de sustentabilidad constituyen una herramienta de desarrollo capaz de brindar informaciones para la planificación de los destinos. El objetivo de esta investigación es desarrollar una propuesta que permita conocer el grado de sustentabilidad de la actividad turística en Galápagos; para ello se seleccionaron 71 indicadores agrupados en dimensiones: 19 ambientales, 30 económicos, 9 sociales, 9 políticos y 4 tecnológicos. Mediante la utilización de la técnica de análisis multicriterio de programación por metas se identifico el índice de sostenibilidad de Galápagos el cuál se encuentra por debajo de los valores deseados, la menor distancia está registrada para la dimensión política, mientras que los temas ambientales registran mayor distancia; esta situación se da debido al acelerado crecimiento del turismo que ha ocasionado mayor flujos migratorios, presión sobre los recursos naturales y el peligro permanente de introducción de especies exóticas que ponen en riesgo la conservación del los ecosistemas de Galápagos. Por lo que se insta a las autoridades instaurar políticas y acciones que minimicen los impactos y garanticen la sostenibilidad para el futuro.
\end{abstract}

PALABRAS CLAVE: Índice de Sustentabilidad; Turismo; Monitoreo; Galápagos.

ABSTRACT: Tourism is an economic activity considered an excellent alternative for the development of destinations. However, economic activities are those that cause the most negative impact on the environment, so it is necessary to take actions to promote the sustainable development of destinations. The sustainability indicators constitute a development tool capable of providing information for the destinations' planning. The goal of this research is to develop a proposal allowing us to know the sustainability degree of tourist activity in Galapagos. For this, 71 indicators grouped into dimensions were selected: 19 environmental, 30 economic, 9 social, 9 political, and 4 technological. Through the use of the multi-criteria analysis technique of programming by goals, the Galapagos sustainability index was identified, which is below the desired values. The least distance is registered for the political dimension, while environmental issues register a greater distance. This situation occurs due to the accelerated growth of tourism that has caused greater migratory flows, pressure on natural resources, and the permanent danger of the exotic species' introduction putting the conservation of the Galapagos ecosystems at risk. Therefore, the authorities must establish policies and actions that minimize impacts and guarantee sustainability for the future.

KEYWORDS: Sustainability Index; Tourism; Monitoring; Galápagos. 


\section{Introducción}

El turismo es reconocido como una actividad económica importante, considerada una excelente alternativa para el desarrollo del destino (COSTA; OLIVEIRA; GOMES, 2010), sin embargo las actividades económicas son las que causan mayor impacto al ambiente (HERNANDEZ; DA SILVA; SANCHEZ, 2019), en este sentido la sustentabilidad del turismo se convierte en una exigencia en la sociedad contemporánea, fundamentalmente en aquellas que dependen del ambiente (ACEVEDO-GUTIÉRREZ; ACEVEDO; BOREN, 2011; BROWLIG; GIBBON, 2009; CUNHA, 2010; DAVIDSON, 2010; HIGHAM; SHELTON, 2011; KOCIOLEK; A.P.; CLAIR; S., 2011; NELSON, 2010; PERSHA; AGRAWAL; CHHATRE, 2011; WITTEMEYER; ELSEN; BEAN; BURTON et al., 2008), por lo que una gestión deficiente puede convertirlo en un factor de degradación, por ello resulta crucial que los países promuevan políticas que soporten el crecimiento del turismo y la sostenibilidad de esta actividad (UNWTO, 2016). Este aspecto resulta de vital importancia, pues su creciente desarrollo ha motivado el interés por el análisis de la sustentabilidad, así como el desarrollo de instrumentos y políticas para la planificación y gestión se ha mantenido en aumento tanto en el debate empresarial como en el científico (SANCHS, 2015; ZSÖGÖN, 2014).

En este sentido la planificación de las actividades turísticas en el contexto actual debe ser cimentada en principios que ofrezcan viabilidad económica, justicia social y equilibrio ambiental a todas las acciones y actividades relacionadas al turismo (PIRES; PHILLIPI JR; RUSCHMANN, 2010). No obstante, en el ámbito del sistema turístico como un todo se nota la actuación del gobierno, de organizaciones no gubernamentales y otras instituciones que conjuntamente componen el espacio institucional y organizacional del turismo (DE OLIVEIRA ARRUDA; PASQUOTTO MARIANI; MORALES DE QUEIROZ CALEMAN, 2014) y son los entes encargados de la toma de decisiones adecuadas para la gestión y planificación de los destinos (FERNÁNDEZ; FERNÁNDEZ, 2014)

Así, se constata que planificar el turismo de forma sustentable es la manera más eficaz de evitar que se produzcan daños irreversibles, de minimizar los costos sociales, económicos y ambientales que afectan a los pobladores de las localidades y de optimizar los beneficios del desarrollo turístico (MACÁRIO DE OLIVEIRA; PASA GÓMEZ, 2013) a tal punto que desde organismos como la Organización Mundial de Turismo (OMT) se insta a los gobiernos a considerar la sostenibilidad como objetivo global y nace lo que se denomina el turismo sustentable.

Las Islas Galápagos son consideradas un laboratorio vivo de biodiversidad tiene como mayor fuente de ingresos económicos al turismo que crece aceleradamente con cifras de 215.000 turistas al año y una taza de crecimiento promedio del 10\% anual (DE GALÁPAGOS, 2014). Sin embargo el incremento del turismo ha generado impactos negativos en el ambiente y ponen en riesgo la conservación del frágil ecosistema insular al punto que la UNESCO en el 2007 colocó a las Islas Galápagos en la lista de patrimonios mundiales en peligro (GRENIER, 2012). En este contexto se plantea al turismo sustentable como modelo de desarrollo de la actividad turística en Galápagos.

Para el logro del turismo sustentable se requiere instrumentos que permitan evaluar el grado de sustentabilidad de la actividad y les proporcione las informaciones necesarias para formular actuaciones y llevar a cabo en los destinos. (PERAL; LOZANO; CASAS; OYOLA, 2010), además monitorear los impactos e 
introducir medidas preventivas que evalúen la situación del destino (PÉREZ-LEÓN; CANIVELL-CRUZ).

En este sentido este estudio tiene como objetivo desarrollar una propuesta que permita monitorear la sustentabilidad del destino Galápagos mediante la creación del índice de sustentabilidad para lo cual se propone la utilización de la Programación por Metas (PM), procedimiento que se encuentra dentro de los Métodos de Decisión Multicriterio, que permiten proporcionar una mejor comprensión del problema y promueven el rol de los participantes en los procesos de toma de decisiones (DOMÍNGUEZ SERRANO; BLANCAS PERAL; GUERRERO CASAS; GONZÁLEZ LOZANO, 2011; PÉREZ; HERNÁNDEZ; GUERRERO; LEÓN et al., 2017).

\section{Materiales y Métodos}

La presente investigación fue realizada en las Islas Galápagos, para lo cual se fundamentó teóricamente la sustentabilidad turística y a partir de un concepto para el destino en estudio se seleccionaron los indicadores de turismo sustentable. Para ello, se siguió procedimientos descritos en la literatura (OMT y otras agencias con experiencias sobre indicadores para el turismo sustentable) se seleccionaron los indicadores considerados apropiados para medir la sustentabilidad turística, se emplearon las propuestas metodológicas planteadas en REED; FRASTER e DOUGILL (2006), que incluyó la participación de los decisores en el proceso. Una vez seleccionados los indicadores, estos fueron agrupados de acuerdo con las diferentes dimensiones establecidas en la conceptualización de sustentabilidad turística asumida y con su tipología: objetivos y subjetivos.

Finalmente se aplicó el procedimiento en el destino objeto de estudio; esto es, el cálculo de la medida global de sustentabilidad a partir de la Programación por Metas con la cuál se calculó el índice de sustentabilidad turística mediante la propuesta desarrollada. Este paso incluyó la determinación de los valores de los indicadores, los niveles de importancia para cada indicador y dimensión y el procedimiento de cálculo. La cuantificación se realizó a través de las diferentes fuentes estadísticas de información existentes. Una vez obtenidos los valores de los índices dimensionales y globales, se procedió al análisis de los resultados con el fin de identificar si las modificaciones en los valores de los indicadores iniciales tienen poca o elevada influencia en el valor obtenido y comparar el comportamiento de las dimensiones en la determinación del valor global de sustentabilidad del destino Galápagos.

\section{Resultados y Discusión}

\section{Cuantificación de los indicadores iniciales}

A través de procedimientos participativos, se determinaron los indicadores necesarios para gestionar la sustentabilidad turística en Galápagos, los cuáles fueron cuantificados consultando diferentes fuentes estadísticas disponibles en diversos estudios como: "Guía práctica para el Desarrollo y uso de indicadores de Turismo Sostenible" con una propuesta de diez indicadores (OMT, 1997); Oficina Europea de Estadísticas (EUROSTAT), OECD y la Comisión Europea con su "Sistema Europeo de Indicadores Turísticos (ESTI) para la Gestión Sustentable" con 20 indicadores con su descripción (COM, 2006); "Guía práctica de Indicadores de desarrollo sostenible para los destinos turísticos", propuesta por la OMT que incluye 
700 indicadores (OMT, 2005); el trabajo realizado por esta organización de conjunto con el PNUMA titulado "Guía práctica para Responsables Políticos: Por un Turismo más Sostenible" con casos reales de varias locaciones del mundo (OMT; PNUMA, 2006).

Adicionalmente, se analizó la propuesta del "Manual de Procedimientos para Entrenadores en Turismo Sustentable", definido a partir de diversas organizaciones que propone 69 indicadores (DÍAZ; NORMAN, 2006) ; indicadores propuestos por la Comunidad Andina en el Taller Regional para Países Andinos sobre Indicadores de Sostenibilidad en Destinos Turísticos en 2005 y otras propuestas de diversos investigadores p.ej: (ÁLVAREZ DÍAZ; VALDÉS PELÁEZ, 2016; ANTONINI, 2009; CHOI; SIRAKAYA, 2006; INSKEEP, 1991; LOZANO-OYOLA; BLANCAS; GONZÁLEZ; CABALLERO, 2012; MACÁRIO DE OLIVEIRA; PASA GÓMEZ, 2013; MAYER, 2008; MILLER, 2001; PINTÉR; HARDI; BARTELMUS, 2005; PULIDO FERNÁNDEZ, 2014; SALINAS; LA O, 2006; SILVA COELHO, 2010; TORRES; SALA RÍOS; FARRÉ PERDIGUER, 2015; YURI HANAI, 2009). Todos ellos emplean diferentes formas de clasificación, así como diversos métodos cualitativos y cuantitativos para su agrupación.

Se obtuvo un conjunto de 71 indicadores, que miden el concepto para el cuál fueron elegidos: 19 ambientales, 30 económicos, 9 sociales, 9 políticos y 4 tecnológicos. Estos se muestran a continuación (Tabla 1) agrupados de acuerdo con la dimensión a la que pertenecen y el signo, que indica la dirección de mejora del indicador en términos de sustentabilidad, es decir signo el signo Positivo (POS) indica que el indicador es del tipo "cuánto más, mejor"; esto es, aquellos para los que un mayor valor representa un mejor grado de sustentabilidad. Por otro lado, los indicadores negativos (NEG) son aquellos para los que un elevado nivel de sustentabilidad se asocia con menores valores de estos indicadores.

Tabla1: Relación de indicadores para la validación del procedimiento.

Table1: List of indicators for the validation of the procedure.

\begin{tabular}{|c|c|c|c|}
\hline Código & Nombre & Signo & Unidad \\
\hline \multicolumn{4}{|c|}{ Dimensión Ambiental } \\
\hline $\mathrm{IA}_{1}$ & Emisiones diarias de $\mathrm{CO}_{2}$ aproximada por embarcación & NEG & gramos \\
\hline $\mathrm{IA}_{2}$ & $\begin{array}{l}\text { Porcentaje de viviendas con servicio higiénico conectado a red pública de alcantarillado o } \\
\text { pozo séptico. }\end{array}$ & POS & $\%$ \\
\hline $\mathrm{IA}_{3}$ & Porcentaje de viviendas con sistema de eliminación de basura por carro recolector. & POS & $\%$ \\
\hline $\mathrm{IA}_{4}$ & Residuos atribuibles (por mes o estación) al turismo. & NEG & Ton/año \\
\hline $\mathrm{IA}_{5}$ & Número de viajes de lanchas de cabotaje inter islas. & POS & $\mathrm{U}$ \\
\hline$I_{A}$ & Porcentaje de especies endémicas del lugar. & POS & $\%$ \\
\hline $\mathrm{IA}_{7}$ & Porcentaje de especies introducidas. & NEG & $\%$ \\
\hline $\mathrm{IA}_{8}$ & Porcentaje de Plantas endémicas del lugar. & POS & $\%$ \\
\hline $\mathrm{IA} 9$ & Estado de conservación de las especies originalmente registradas en Galápagos. & POS & $\%$ \\
\hline $\mathrm{IA}_{10}$ & Número de especies endémicas. & POS & $U$ \\
\hline $\mathrm{IA}_{11}$ & Número de turistas por $\mathrm{Km}^{2}$ de sitio & NEG & Ratio \\
\hline $\mathrm{IA}_{12}$ & $\begin{array}{l}\text { Porcentaje de la población que vive en condiciones de alta vulnerabilidad (medido para el } \\
\text { evento tsunami) }\end{array}$ & NEG & $\%$ \\
\hline
\end{tabular}

Continua... 
....continuación.

\begin{tabular}{|c|c|c|c|}
\hline Código & Nombre & Signo & Unidad \\
\hline $\mid A_{13}$ & Residuos diarios de barcos de turismo (Promedio) & NEG & Ton/día \\
\hline $\mathrm{IA}_{14}$ & Visitas a PN Galápagos con Respecto al Total de Visitas a Parques Nacionales en Ecuador & POS & $\%$ \\
\hline $\mathrm{IA}_{15}$ & $\begin{array}{l}\text { Porcentaje de viviendas con energía eléctrica proveniente de Fuentes de Energía } \\
\text { Renovable (Paneles Solares) }\end{array}$ & POS & $\%$ \\
\hline $\mathrm{IA}_{16}$ & Consumo de agua del sector turístico al año & NEG & $\mathrm{m}^{3}$ \\
\hline $\mathrm{IA}_{17}$ & Consumo de energía del sector turístico al año & NEG & TJ/año \\
\hline $\mathrm{IA}_{18}$ & Eventos de Educación Ambiental desarrollados. & POS & U \\
\hline $\mathrm{IA}_{19}$ & Estudiantes y residentes involucrados en actividades de educación ambiental en el destino. & POS & $\mathrm{U}$ \\
\hline \multicolumn{4}{|c|}{ Dimensión Económica } \\
\hline $\mathrm{IE}_{1}$ & Número promedio de turistas mensuales. & POS & $\mathrm{U}$ \\
\hline $\mathrm{IE}_{2}$ & Proporción de turistas en el mes de máxima y mínima afluencia. & NEG & Ratio \\
\hline $\mathrm{IE}_{3}$ & Número total de turistas (nacionales y extranjeros al año). & POS & $\mathrm{U}$ \\
\hline $\mathrm{IE}_{4}$ & Número de turistas nacionales (al año). & POS & $\mathrm{U}$ \\
\hline $\mathrm{IE}_{5}$ & Proporción de turistas extranjeros con respecto a los nacionales & NEG & Ratio \\
\hline $\mathrm{IE}_{6}$ & Relación de turistas año actual con respecto al año anterior & POS & Ratio \\
\hline $\mathrm{IE}_{7}$ & $\begin{array}{l}\text { Número total de empleados del sector turístico. (Personal Ocupado en Establecimientos } \\
\text { Registrados MINTUR) }\end{array}$ & POS & Ratio \\
\hline $\mathrm{IE}_{8}$ & Proporción entre hombres y mujeres empleados en el turismo. & POS & Ratio \\
\hline $\mathrm{IE}_{9}$ & Porcentaje del empleo en el sector turístico con respecto al empleo total. & POS & $\%$ \\
\hline $\mathrm{IE}_{10}$ & Salario básico (mensual) de los empleados en Galápagos. & POS & USD \\
\hline $\mathrm{IE}_{11}$ & Costo de la canasta básica promedio mensual. & NEG & USD \\
\hline $\mathrm{IE}_{12}$ & Gasto medio diario por turista. & POS & USD \\
\hline $\mathrm{IE}_{13}$ & Porcentaje de los ingresos generados por el turismo que permanecen en las islas & POS & $\%$ \\
\hline $\mathrm{IE}_{14}$ & Tasa de crecimiento poblacional intercensal promedio anual & NEG & Ratio \\
\hline $\mathrm{IE}_{15}$ & Índice de turistas sobre la población local. & NEG & Ratio \\
\hline $\mathrm{IE}_{16}$ & Proporción del número de turistas entre el mes de máxima y mínima afluencia. & NEG & Ratio \\
\hline $\mathrm{IE}_{17}$ & Estancia promedio en Galápagos & POS & días \\
\hline $\mathrm{IE}_{18}$ & Estadía promedio de visitantes a bordo. & POS & días \\
\hline $\mathrm{IE}_{19}$ & Estadía promedio de visitantes en tierra. & POS & días \\
\hline $\mathrm{IE}_{20}$ & Índice de GINI (Galápagos). & NEG & $\%$ \\
\hline $\mathrm{IE}_{21}$ & $\begin{array}{l}\text { Porcentaje de recaudación tributaria de los hoteles y restaurantes de Galápagos con } \\
\text { respecto al total del país }\end{array}$ & POS & $\%$ \\
\hline $\mathrm{IE}_{22}$ & PARTICIPACIÓN PORCENTUAL DEL VAB POR PROVINCIA & POS & $\%$ \\
\hline $\mathrm{IE}_{23}$ & $\begin{array}{l}\text { Porcentaje de establecimientos de alojamiento Registrados en MINTUR con respecto al } \\
\text { total Nacional. }\end{array}$ & POS & $\%$ \\
\hline $\mathrm{IE}_{24}$ & Porcentaje de habitaciones Registrados en MINTUR con respecto al total nacional. & POS & $\%$ \\
\hline $\mathrm{IE}_{25}$ & Porcentaje de camas registradas en el MINTUR con respecto al total nacional & POS & $\%$ \\
\hline $\mathrm{IE}_{26}$ & Porcentaje de plazas-cama con respecto al total nacional & POS & $\%$ \\
\hline $\mathrm{IE}_{27}$ & Plazas-cama por habitante. & POS & Ratio \\
\hline $\mathrm{IE}_{28}$ & $\begin{array}{l}\text { Distribución porcentual de los establecimientos de alojamiento de categoría única con } \\
\text { respecto al total nacional. }\end{array}$ & POS & $\%$ \\
\hline $\mathrm{IE}_{29}$ & Número de dispositivos de transporte marítimo y fluvial para uso turístico. & POS & $U$ \\
\hline $\mathrm{IE}_{30}$ & Número de dispositivos de transporte terrestre para uso turístico. & POS & $\mathrm{U}$ \\
\hline
\end{tabular}

Continua... 
....continuación.

\begin{tabular}{|c|c|c|c|}
\hline Código & Nombre & Signo & Unidad \\
\hline \multicolumn{4}{|c|}{ Dimensión Social } \\
\hline $\mathrm{ISc}_{1}$ & Número de guardaparques, recibieron capacitación sobre monitoreo turístico & POS & U \\
\hline $\mathrm{ISc}_{2}$ & $\begin{array}{l}\text { Número de funcionarios que obtuvieron certificación por competencias laborales en el perfil } \\
\text { de Operaciones de Protección de Parques y Reservas, orientado a guardaparques de las } \\
\text { áreas protegidas del archipiélago }\end{array}$ & POS & $\mathrm{U}$ \\
\hline $\mathrm{ISc}_{3}$ & Población Flotante de visitantes. & NEG & $U$ \\
\hline $\mathrm{ISc}_{4}$ & Proporción entre turistas y población autóctona (mes de máxima afluencia). & NEG & Ratio \\
\hline $\mathrm{ISC}_{5}$ & Tasa anual de crecimiento entre los pobladores permanentes de las islas & Ratio & Ratio \\
\hline $\mathrm{ISc}_{6}$ & Promedio de años de escolaridad. & POS & Años \\
\hline $\mathrm{ISC}_{7}$ & Tasa de crecimiento anual intercensal de la vivienda en Galápagos. & NEG & $\%$ \\
\hline ISc8 & Porcentaje de Emigración neta de la Comunidad & NEG & $\%$ \\
\hline ISc9 & Porcentaje de hogares con acceso al agua proveniente de red pública. & POS & $\%$ \\
\hline \multicolumn{4}{|c|}{ Dimensión Política } \\
\hline $\mathrm{IP}_{1}$ & Repartición de la Tasa de Ingreso al Parque Nacional Galápagos destinada al PNG. & POS & $\%$ \\
\hline $\mathrm{IP}_{2}$ & $\begin{array}{l}\text { Repartición de la Tasa de Ingreso al Parque Nacional Galápagos para la Agencia de } \\
\text { Regulación y Control de la Bioseguridad y Cuarentena para Galápagos }\end{array}$ & POS & $\%$ \\
\hline $\mathrm{IP}_{3}$ & $\begin{array}{l}\text { Porcentaje de instituciones de las islas tienen planes de contingencia actualizados (para } \\
\text { Tsunami) }\end{array}$ & POS & $\%$ \\
\hline $\mathrm{IP}_{4}$ & Número de Reportes de guías naturistas analizados con respecto a los recibidos & POS & $\%$ \\
\hline $\mathrm{IP}_{5}$ & $\begin{array}{l}\text { Número de proyectos de investigación científica aprobados por la DPNG (Dir, del Parque } \\
\text { Nac. Galápagos) }\end{array}$ & POS & $U$ \\
\hline $\mathrm{IP}_{6}$ & Inspección de estándares ambientales a embarcaciones que ingresan u operan en la RMG & POS & $\mathrm{U}$ \\
\hline $\mathrm{IP}_{7}$ & Licencias de Pescadores artesanales renovadas (PARMA) & POS & $\mathrm{U}$ \\
\hline $\mathrm{IP} 8$ & Porcentaje de retención de organismos protegidos en revisiones de equipajes realizadas & NEG & $\%$ \\
\hline $\mathrm{IP}_{9}$ & $\begin{array}{l}\text { Porcentaje de infracciones detectadas en patrullajes terrestres para el control del uso de la } \\
\text { tierra }\end{array}$ & NEG & $\%$ \\
\hline \multicolumn{4}{|c|}{ Dimensión Tecnológica } \\
\hline $\mathrm{IT}_{1}$ & Usuarios de Internet por cada 100 habitantes. & POS & Ratio \\
\hline $\mathrm{IT}_{2}$ & Porcentaje de personas que utilizan la computadora. & POS & $\%$ \\
\hline $\mathrm{IT}_{3}$ & Porcentaje de personas que tienen teléfono celular activado por provincia. & POS & $\%$ \\
\hline $\mathrm{IT}_{4}$ & Porcentaje de turistas que utiliza internet para planificar su viaje a Galápagos. & POS & $\%$ \\
\hline
\end{tabular}

Fuente: Elaboración propia.

Source: self made.

Se debe mencionar que el signo también informa acerca del carácter multicriterio de la sustentabilidad turística, principalmente por la contraposición de criterios, tanto dentro de una misma dimensión como entre diferentes dimensiones.

Por ejemplo, con indicadores o criterios dentro de una misma dimensión aparece el número total de turistas ( $\left.\mathrm{IE}_{3}\right)$, con signo positivo, pues se desea que este indicador tenga valores altos. Un elevado número de turistas en un destino evidencia un alto grado de preferencia frente al resto de sus competidores y puede ser útil para demostrar la fortaleza de esta actividad económica en el destino. Tal es el caso, que es uno de los indicadores principales que recogen las informaciones turísticas como 
indicadores de elevado nivel de desarrollo turístico. Además, se reconoce como uno de los principales indicadores de sustentabilidad desde el punto de vista económico.

Por su parte, dentro de la misma dimensión, aparece el índice de turistas entre la población local ( $\left.\mathrm{IE}_{15}\right)$, cuyo signo es negativo, pues mientras mayor número de turistas por pobladores existe en el destino, menos posibilidades tienen los locales de disfrutar de los servicios brindados, suelen aumentar los precios de los bienes y servicios que demandan el conjunto pobladores y visitantes, y se dificulta el acceso a los principales sitios. Dicha situación responde al típico patrón del turismo, donde hay una demanda creciente de bienes y servicios que a la larga deja menos ganancias en la economía local y desplaza a los residentes (BARRIGA, 2015)

De este modo, es tarea de la sustentabilidad encontrar una solución de compromiso entre ambos indicadores; esto es, determinar el número de turistas que proporcionen ingresos económicos deseables para impulsar el desarrollo del destino: No obstante, este valor (número de turistas) debe ser tal que afecte lo menos posible el acceso de los pobladores a los principales sitios, en el disfrute de los atractivos y que no provoque escases de bienes y servicios por superpoblación.

Otro de los ejemplos que demuestran la necesidad de encontrar soluciones de compromiso se da entre indicadores incluidos en diferentes dimensiones, como el $\mathrm{IE}_{3}$ número total de turistas (económico y positivo) y el $\mathrm{IA}_{11}$, número de turistas por $\mathrm{Km}^{2}$ de sitio (ambiental y negativo), pues se asume que mientras más turistas hay por dimensión especial, mayor será el daño medioambiental ocasionado por la utilización de los recursos naturales disponibles. Más, si es el caso de un área como Galápagos, con un elevado grado de protección natural y, por consiguiente, alta demanda de conservación de sus recursos, de los cuales depende el desarrollo de la actividad turística.

De ahí, la justificación de la elección de un procedimiento basado en la Decisión Muilticriterio para el análisis de la sustentabilidad de Galápagos. Esto está ocasionado porque en los problemas de programación multicriterio no existe una solución que optimice todos los criterios a la vez, dada la situación de conflicto entre ellos, por lo cual, se deben encontrar soluciones de compromiso (MUNDA, 2008). Este comportamiento es similar al que ocurre en temas de sustentabilidad.

En la Figura 1 se detalla la composición del conjunto de indicadores para los cuales se obtuvo la información. Como se aprecia, existe, un predominio de los aspectos económicos frente al resto y los indicadores ambientales le siguen en número. Ello es evidencia de la marcada importancia que han tenido los temas económicos sobre el resto, históricamente. Asimismo, queda demostrado en los datos estadísticos, donde las cuestiones económicas tienen mayor facilidad para ser cuantificadas existe mayor disponibilidad de datos.

En ese sentido es importante proponer el aumento de la disponibilidad de información de datos e indicadores de tipo ambiental. Estos son, en definitiva, aquellas cuestiones que garantizan la permanencia de Galápagos como un destino de preferencia, pues constituyen sus ventajas comparativas. De ahí, la necesidad de investigaciones de este tipo, para contribuir con la conservación de los recursos naturales del destino, los cuales constituyen su principal atractivo y motivo de visita.

De forma general, el carácter compensatorio del procedimiento propuesto permitirá hacer una aproximación más cercana a la sustentabilidad. En primer lugar, porque el establecimiento de las metas posibilita determinar cuál es la situación ideal 
de sustentabilidad para cada uno de los indicadores o criterios a través de los que se va a evaluar el destino. Segundo, porque en los valores de los índices, tanto los dimensionales como el global, comportamientos negativos/positivos en algunos indicadores, serán contrarrestados con valores opuestos positivos/negativos en otros incluidos en el procedimiento de cálculo.

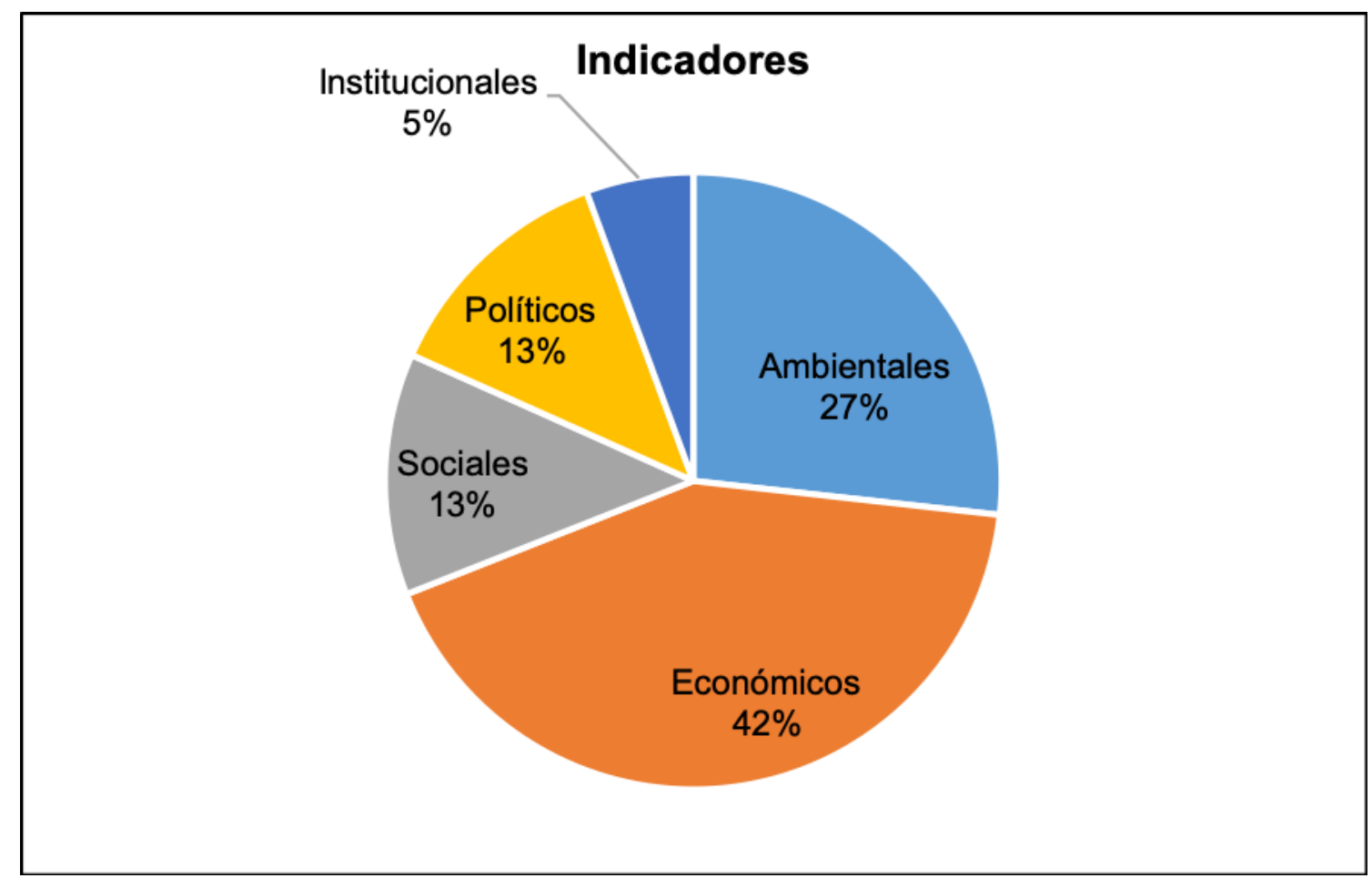

Figura 1: Distribución del conjunto de indicadores.

Figure 1: Distribution of the set of indicators.

Fuente: Elaboración propia. Source: self made.

\section{Determinación de los niveles de aspiración}

En lo referente al establecimiento de los niveles de aspiración. Para los indicadores positivos expresados en porcentaje, se determinó el 100\% como valor deseado. Para estos mismos, pero del tipo negativo, se trabajó con valor 1 . No se pudo proponer el valor cero porque indefinía la expresión de cálculo para normalizar las puntuaciones.

Los ratios, como el $\mathrm{IE}_{2}$ e IE $\mathrm{IE}_{8}$, se desean que tomen valor 1. Por su parte, el IT 1 tiene un valor tan bajo que se desea un aumento hasta la unidad, inicialmente, y así sucesivamente.

Por su parte, los medidos en unidades y para los que no se dispone de información acerca del valor deseado, los decisores consensuaron aumentos / disminuciones (en dependencia de si son positivos/negativos) de entre el 15 y el $25 \%$ aproximadamente. 


\section{Ponderación y Agregación}

El proceso de ponderación o determinación de pesos o niveles de importancia de los indicadores puede llevarse a cabo de diversas maneras, tal como se refleja en la bibliografía especializada. Ante la ausencia de fuentes de información o decisores consensuados, de acuerdo con el concepto de sustentabilidad, se determinó aplicar el procedimiento de "ponderación Equitativa". Este asume que todas las dimensiones tienen igual importancia, coincidiendo con el concepto de sustentabilidad, en el que todas las dimensione que lo agrupan son igualmente importantes. Téngase en cuenta que, un valor negativo en cualquier dimensión afecta el desempeño global de la sustentabilidad de un destino. De modo que, el peso o ponderación de cada una es como sigue:

$$
\omega_{i}=\frac{1}{m} \text {, donde: }
$$

$\overline{\omega_{i}}$ : Ponderación de la i-ésima dimensión

$m$ : número de dimensiones $(\mathrm{i}=1,2, \ldots, \mathrm{m})$.

De este modo, el peso para el j-ésimo indicador de la i-ésima dimensión vendría dado por:

$$
\omega_{i j}=\frac{\omega_{i}}{n} \text {, donde: }
$$

$\overline{\omega_{i}}$ : Ponderación de la $i$-ésima dimensión.

$n$ : número de indicadores $(j=1,2, \ldots, n)$ de la $i$-ésima dimensión.

\section{Índice de Sustentabilidad}

En referencia a los resultados para el índice de sustentabilidad del destino Galápagos $\left(I S_{G}\right)$. Este puede tomar valores positivos o negativos o cero. El valor cero corresponde a aquellas metas que se satisfacen exactamente; es decir, cuando el indicador que se analiza toma valor igual a su nivel de aspiración. Este es el caso en que ambas variables de desviación toman valor cero, para cualquier tipo de indicador, positivo o negativo.

El valor negativo se asocia con falta de logro en las metas o criterios de sustentabilidad, o lo que es lo mismo, las variables de desviación no deseadas (debilidades) para un indicador positivo/negativo $\left(\overline{n_{j}^{+} / p_{j}^{-}}\right)$, toman valores mayores que cero. Este valor denota la cuantía en que la meta no se satisface; esto es, la lejanía a la situación de sustentabilidad deseada. Por el contrario, cuando el índice toma valor positivo, denota que el criterio evaluado (indicador) tiene un valor superior al nivel de aspiración; por lo tanto, la meta de sustentabilidad correspondiente a ese criterio fue alcanzada y, más aún, sobre cumplida. En este punto, las variables de desviación no deseadas toman valor cero, mientras que las fortalezas para el indicador positivo/negativo $\left(\overline{p_{j}^{+} / n_{j}^{-}}\right)$, toman valores mayores que cero.

Como el $I S_{G}$ está concebido para la compensación entre las fortalezas y las debilidades, en raras ocasiones toma valor cero, pues es poco frecuente que el $100 \%$ de los indicadores analizados tomen exactamente el valor establecido como deseado. En la Figura 2 muestra las posibilidades de valoración del índice, pudiéndose alcanzar valores menores que -1 y mayores que 1 . 


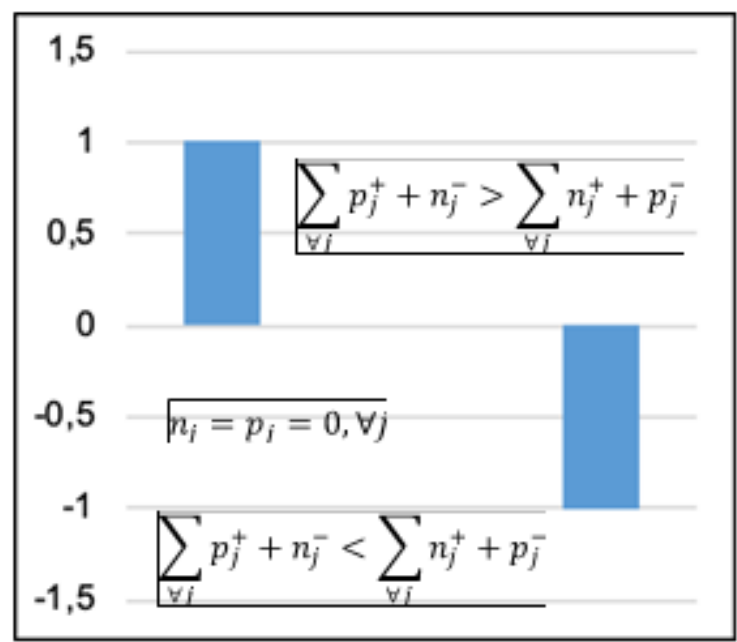

Figura 2: Rango aproximado del $I_{G}$ Figure 2: Approximate ISG Range Fuente: Elaboración propia.

Source: self made.

Una situación ideal de sustentabilidad tendría valor 0; esto es, todas las metas se satisfacen exactamente. Valor 1 correspondería al caso, poco probable, en que los indicadores sobrepasaran los niveles de aspiración, exactamente, en un $100 \%$. Mientras tanto, el valor -1 responde a la situación en que los valores de sustentabilidad fueran un $100 \%$ menor que el valor deseado.

En la Tabla 2 a continuación aparecen los resultados del ISG, para cada una de sus dimensiones y de forma global (TABLA 2). Como se observa, tanto el índice global como los indicadores dimensionales denotan falta de sustentabilidad. Todos con valor por debajo de cero.

Tabla 2: Valores del IS $\mathrm{G}$ y por dimensiones.

Table 2: IS $\mathrm{G}$ values and by dimensions

\begin{tabular}{|l|c|}
\hline IS \\
\hline IS. Ambiental & $-0,4,4162$ \\
\hline IS. Económico & $-0,1201$ \\
\hline IS. Social & $-0,2313$ \\
\hline IS. Político & $-0,0707$ \\
\hline IS. Tecnológico & $-0,1094$ \\
\hline
\end{tabular}

Fuente: Elaboración propia.

Source: self made.

El valor global de sustentabilidad del destino Galápagos se constituye por la sumatoria de los índices dimensionales. Globalmente, el nivel de sustentabilidad del destino se encuentra por debajo del valor deseado. De conjunto, tiene un valor cercano al que tomarían si la totalidad de los indicadores estuviera un $100 \%$ por debajo del nivel de aspiración deseado. Las contribuciones de cada dimensión al índice se detallan en las Figuras 3 y 4. 


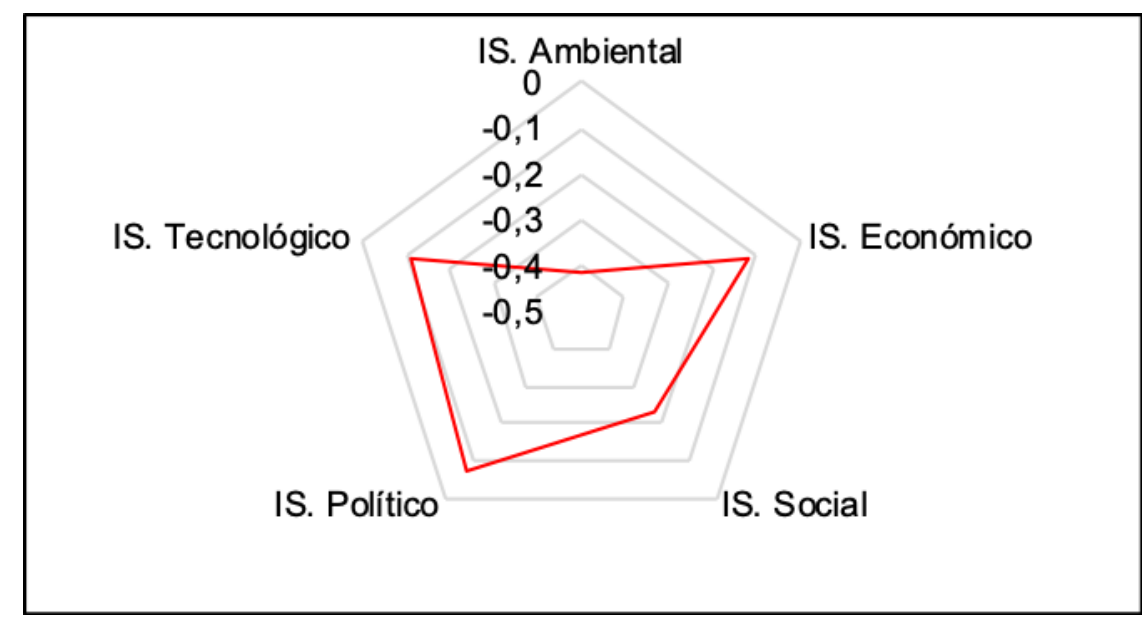

Figura 3: Contribución de las dimensiones al ISG.

Figure 3: Contribution of dimensions to the $I_{S_{G}}$.

Fuente: Elaboración propia. Source: self made.

La mayor aportación, en sentido negativo, la tiene la dimensión ambiental, estos son los principales problemas o criterios que se deben considerar. Son las cuestiones que mayor consentimiento demandan y las que, de forma global, más alejadas se encuentran de los niveles de aspiración definidos (Figura 3, parte más cercana al valor central -0.5).

La segunda mayor puntuación (negativa) corresponde a los aspectos sociales. Esta dimensión, a pesar de no ser la que más indicadores incluye, tiene en su contra que es aquella en que, de forma general, más alejados están sus valores de los niveles deseados de sustentabilidad. Análogamente, podría pasar que el desempeño no favorable en alguno o varios indicadores, sea tal, que ningún comportamiento favorable (en términos absolutos) lo pueda mitigar.

Por su parte, la dimensión económica es la que mayor cantidad de indicadores contiene; sin embargo, reflejan, de conjunto, una mejor sustentabilidad que el resto de las dimensiones anteriormente señaladas. Esta afirmación podría hacerse también con respecto al resto de las dimensiones, pues la económica alberga más del triple de las dimensiones social y política y, los indicadores tecnológicos representan casi la octava parte de la dimensión económica.

En ese orden negativo decreciente le siguen las dimensiones tecnológica y política. La primera, con solo cuatro indicadores tiene un valor absoluto mayor (de forma negativa) que la política, con nueve indicadores. Por ello, los aspectos tecnológicos requieren una mayor atención en función de mejorar el nivel global de sustentabilidad. 


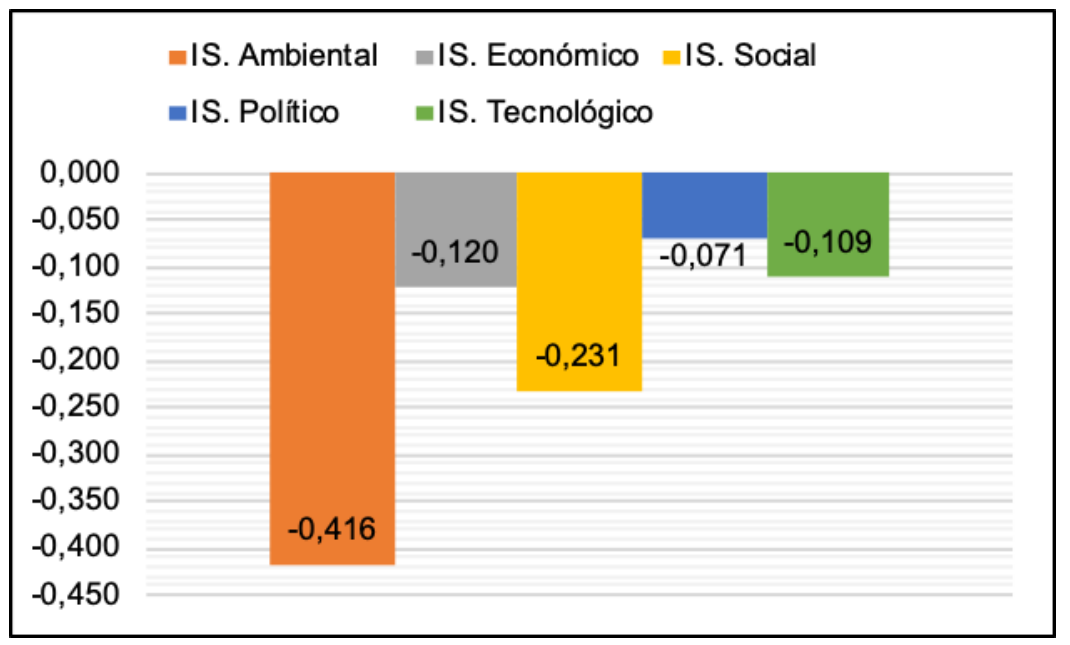

Figura 4: Indicadores Dimensionales de Sustentabilidad para el destino Galápagos. Figure 4: Dimensional Indicators of Sustainability for the Galapagos destination.

Fuente: Elaboración propia. Source: self made.

A continuación, se muestran las distancias dimensionales y la global a la situación deseada de sostenibilidad. Estas serían de 0.2 para cada dimensión y de 1 para el índice global. Esta es la situación, poco probable, en que cada indicador tome un valor exactamente igual al que se fije como nivel de aspiración (Figura 5, primeras cinco barras, de abajo hacia arriba). Mientras tanto, la parte superior muestra la distancia que hay entre la situación actual de sustentabilidad (global y por dimensión) y la deseada. Como se aprecia, la menor distancia está registrada para la dimensión política, mientras que los temas ambientales, como se dijo anteriormente, son los que mayor contribución deberían hacer. Esto no es más que resolver los problemas asociados a esta dimensión de modo que los indicadores aumenten sus valores y los aspectos negativos se mitiguen o compensen con los positivos.

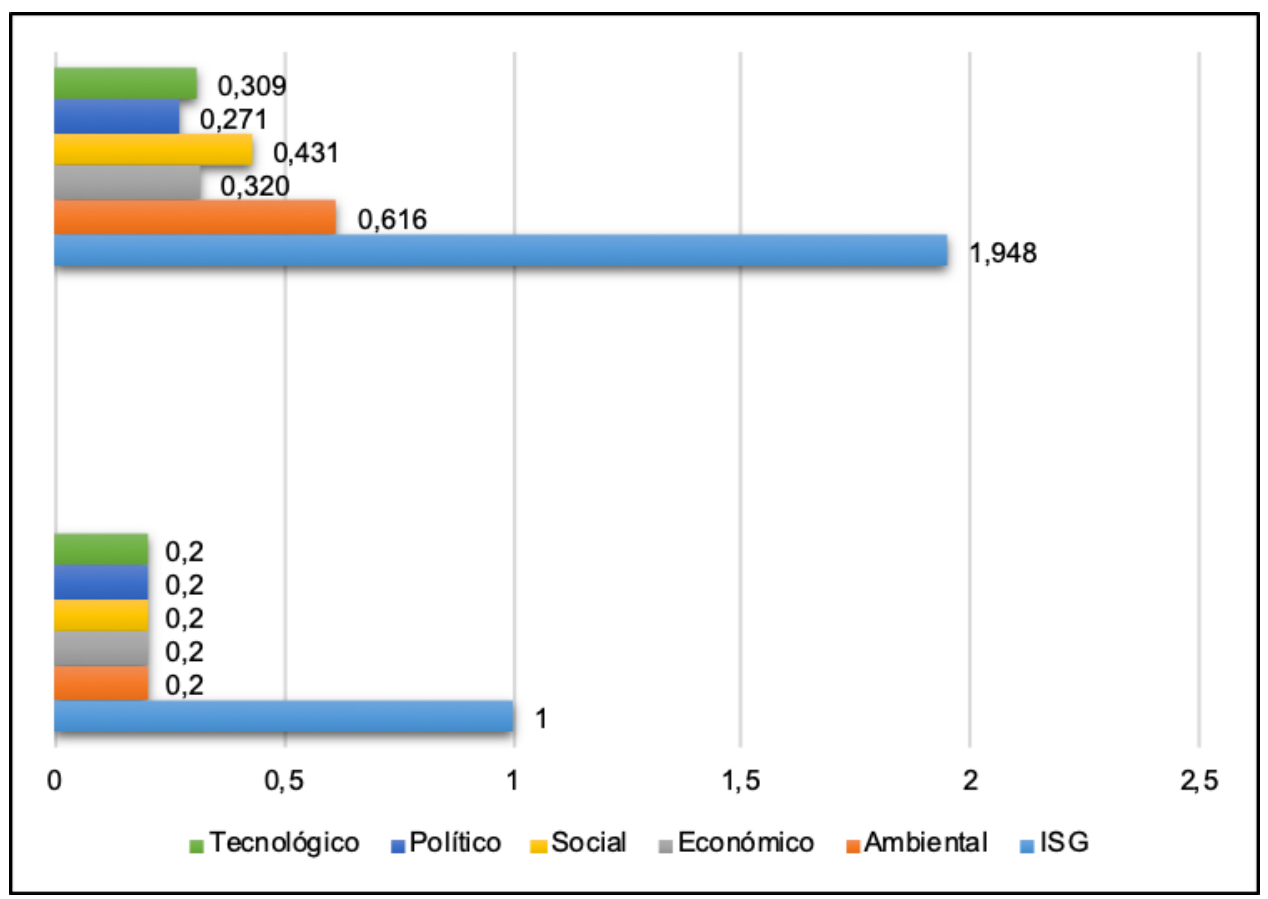

Figura 5: Distancia entre la situación de sustentabilidad actual y la deseada. Figure 5: Distance between the current and desired sustainability situation.

Fuente: Elaboración propia. Source: self made. 
Mientras que el ISG ofrece una visión global de la sustentabilidad del destino, una característica deseable es que pueda ser descompuesto de modo que sea capaz de poderse identificar la contribución de cada componente al índice global.

Desde el punto de vista dimensional, la peor situación corresponde a la dimensión ambiental con un valor de -0.4162 (Figura 5). Esta dimensión cuenta con 19 indicadores, de los cuales solo tiene como fortalezas el número de especies endémicas $\left(\mathrm{IA}_{10}\right)$, que cumple la meta exactamente en el valor deseado y el indicador representativo de la elección del Parque Nacional Galápagos sobre el resto de los Parques Nacionales de Ecuador por parte de los visitantes $\left(I_{14}\right)$, que constituye su mayor fortaleza en términos de sustentabilidad. Sin embargo, su valor no fue tan elevado que contribuyera a realizar un aporte al índice ambiental de forma tal que su valor global fuera positivo.

A pesar de ser la dimensión con mayor valor negativo, al menos el $10,53 \%$ de sus indicadores obtuvieron valores por encima del nivel deseado en correspondencia con la sustentabilidad (Figura 6).

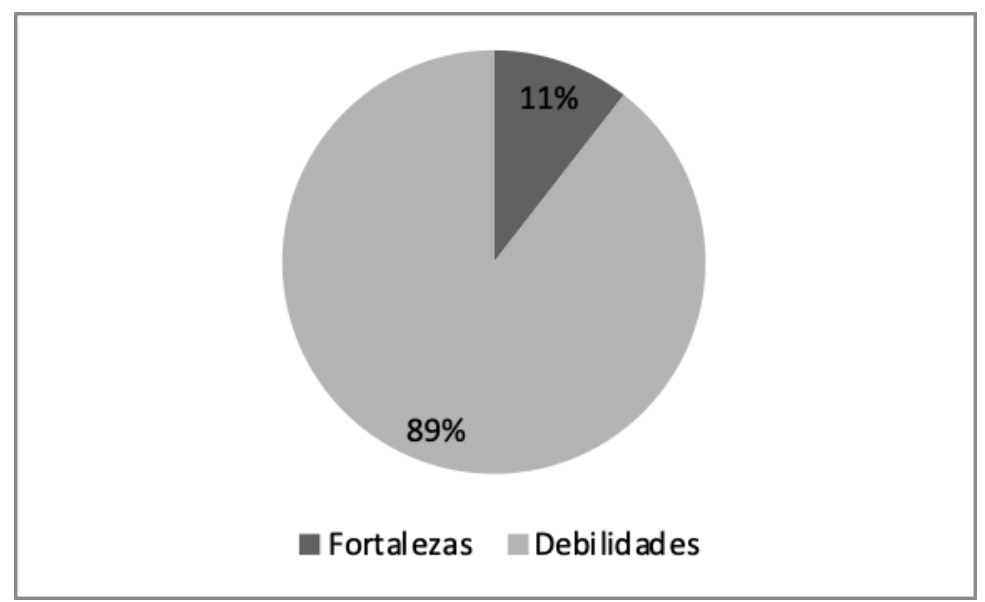

Figura 6: IS. Ambiental.

Figure 6: IS. Environmental.

Fuente: Elaboración propia. Source: self made.

Los indicadores que obtuvieron valores cercanos al nivel deseado de sustentabilidad, pero por debajo de este fueron el $\mathrm{IA}_{2}$ (Porcentaje de viviendas con servicio higiénico conectado a red pública de alcantarillado o pozo séptico) y el $I A_{3}$ (Porcentaje de viviendas con sistema de eliminación de basura por carro recolector) que contribuyen directamente con la limpieza del destino y a la posibilidad de recolección de materias primas, con fines de su reutilización. Representan servicios sociales que tributen directamente con la sustentabilidad ambiental del destino.

El resto de los indicadores no supera el nivel de aspiración empleado, siendo el más preocupante el $\left(\mathrm{I}_{7}\right)$ "Porcentaje de especies introducidas". Este es un indicador clave, pues las especies introducidas pueden actuar de forma negativa en los ecosistemas, alterando su funcionamiento y contribuyendo, en muchas ocasiones, a la desaparición de otras especies.

La combinación de industrias turística y pesquera en auge, el crecimiento demográfico y la demanda logística versus controles débiles de bioseguridad hacen peligrar directamente el aislamiento de Galápagos. Mientras que las especies introducidas a través del transporte de carga pueden tener un impacto prácticamente ilimitado en la flora y la fauna nativas de las islas, las enfermedades "imprevistas" de 
plantas y plagas también pueden afectar el bienestar económico y sanitario de los residentes humanos. Es por ello, que las actuales y futuras regulaciones, así como las políticas y cursos de acción en función de la sustentabilidad medioambiental deben estar encaminadas en obtener mejores resultados para este indicador, entre la gran mayoría de los indicadores ambientales analizados.

Otro de los aspectos que más atención demanda en la arista medioambiental es la población que vive en condiciones de alta vulnerabilidad (medido para el evento tsunami) ( $\left(\mathrm{A}_{12}\right)$, cuyo valor, ponderado, también se encuentra cerca de la situación deseada. Este indicador se considera importante, por cuanto permite reducir el nivel de daños ocasionados por fenómenos climatológicos externos. Tal es el caso, que una reducción de su valor, a uno cercano al nivel de aspiración pondría al destino en una situación favorable de sustentabilidad, por cuanto reduce, en gran medida, la probabilidad de pérdida de bienes materiales y vidas humanas ante fenómenos como los tsunamis.

Este, sin lugar a duda, contribuye a medir la exposición a niveles de riesgos. En ese sentido, los destinos turísticos han empezado a buscar posibles formas de reducir las emisiones en cada sector o mitigar sus efectos negativos y a adaptarse con cambios de planificación y construcción que palien los daños potenciales de los fenómenos climatológicos.

El valor del índice de sustentabilidad para la dimensión económica es de 0.120 (Tabla 23). Esta puntuación, al igual que el anterior, indica la falta de logro en cuanto a la sustentabilidad. De los 30 indicadores que componen esta dimensión, solo el $20 \%$ (seis indicadores) constituyen fortalezas; esto es, que alcanzan, al menos, el nivel de aspiración deseado (Figura 7). Todos estos son de tipo positivo: el Número promedio mensual de turistas $\left(\mathrm{IE}_{1}\right)$, el Número total de turistas (nacionales y extranjeros al año) ( $\left.\mathrm{IE}_{3}\right)$, que a su vez es el único de estos que sobrepasa el nivel de aspiración planificado.

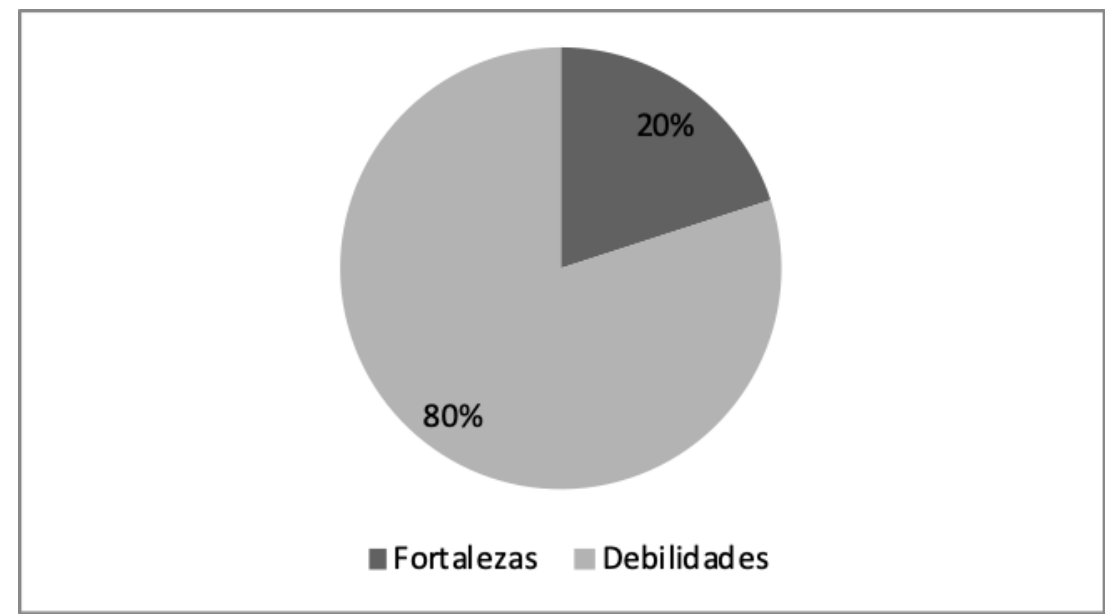

Figura 7: IS. Económica.

Figure 7: IS. Economical

Fuente: Elaboración propia. Source: self made.

Este $\left(\mathrm{IE}_{3}\right)$ es uno de los indicadores más controversiales en cuanto a la sustentabilidad, pues a pesar de ser reconocido, a nivel mundial, como uno de los indicadores más importantes en la industria turística, en muchas ocasiones, y principalmente en los sitios vulnerables y con determinado grado de protección, lo ideal es que el valor de este indicador no creciera mucho, en función de conservar 
las condiciones naturales del destinos. Tal es el caso de Galápagos, que tiene como fortaleza el elevado número de visitantes en el año, lo que supone un buen desempeño económico. Mientras tanto, ese elevado número de indicadores eleva la densidad de turistas por $\mathrm{Km}^{2}$, lo que constituye una característica no deseable desde el punto de vista ambiental.

Siguiendo el análisis en el orden económico, los restantes indicadores que clasifican como fortalezas para el destino son el número de turistas nacionales que acuden al destino (al año) ( $\mathrm{IE}_{4}$ ), el Salario básico (mensual) de los empleados en Galápagos ( $\left.\mathrm{IE}_{10}\right)$, Número de dispositivos de transporte marítimo y fluvial para uso turístico $\left(\mathrm{IE}_{29}\right)$ y el Número de dispositivos de transporte terrestre para uso turístico $\left(\mathrm{IE}_{30}\right)$.

$\mathrm{El} \mathrm{IE} 4$ demuestra la preferencia de los nacionales por visitar el destino. Desde el punto de vista de la demanda, este es un aspecto deseable, pues los turistas nacionales complementan las disponibilidades de habitaciones y plazas-cama que no son ocupados por turistas extranjeros, además, contribuyen a los ingresos turísticos del destino. Desde el punto de vista de la demanda cabe destacar que, frente a los elevados costes de desplazamiento internacional, el traslado hacia un destino del mismo país sobresale como una buena opción para los turistas nacionales. Por su parte, el $\mathrm{IE}_{10}$ informa sobre el poder de compra de los pobladores. Aun cuando el salario medio no es superior al costo de la canasta básica media mensual en el destino, el incremento del salario medio contribuye a garantizar acceso de los pobladores a determinados recursos que, en ocasiones, se encarecen en el destino por causa de la actividad turística.

Mientras tanto, los indicadores $\mathrm{IE}_{29}$ e $\mathrm{IE}_{30}$ ofrecen una buena visualización de la situación del transporte para el uso turístico en el destino. Ambos, tanto para el transporte marítimo como el terrestre se presentan como fortalezas desde el punto de vista económico. Ambos indicadores requieren importancia porque son un componente fundamental en la sustentabilidad económica, tanto para el traslado hacia el destino como dentro de este, para visitar los principales atractivos. Esto es parte también de la accesibilidad, que constituye una cuestión básica en la sustentabilidad económica de los destinos turísticos.

Las debilidades más acentuadas; es decir, aquellos indicadores que más alejados están de la situación deseada fueron la tasa de crecimiento poblacional inter censal promedio anual (IE $\mathrm{IE}_{14}$ ), la proporción del número de turistas entre el mes de máxima y mínima afluencia ( $\left.\mathrm{IE}_{16}\right)$ y el Índice de GINI (Galápagos) ( $\mathrm{IE}_{20}$ ). EI primero, mide el crecimiento poblacional entre un censo y otro. Es demostrativo del aumento de la densidad poblacional, lo cual es un factor no deseable, teniendo en consideración el escaso porcentaje habitable de las islas, así como el creciente número de turistas, lo que ocasiona que aumente el uso de los espacios destinados a la vivienda en relación con las posibilidades reales espaciales y la sobrepoblación de las áreas en determinados momentos pico; sobre todo, en la temporada alta. Este crecimiento es debido también a la posibilidad de encontrar trabajo en el sector del turismo, principalmente. Investigaciones recientes realizadas en el destino indican que los residentes locales culpan a los inmigrantes por muchos de los problemas del archipiélago, como por ejemplo la ausencia de una conciencia ambiental, la basura y además los responsabilizan de usurpar los trabajos. Dicha situación responde al típico patrón del turismo, donde hay una demanda creciente de bienes y servicios que a la larga deja menos ganancias en la economía local y desplaza a los residentes (BARRIGA, 2015) 
El IE $_{16}$ mide el aspecto relativo con la estacionalidad del turismo. Esta proporción es una medida para tomar decisiones sobre la infraestructura y los servicios. En este caso, lo que se desea es la mayor similitud posible entre los picos (máxima y mínima), de modo que el declive del número de visitantes en temporadas bajas no provoque el cierre de negocios, el aumento de trabajadores a tiempo parcial, etc.

Finalmente, el índice de GINI $\left(\mathrm{IE}_{20}\right)$ es el indicador de desigualdad por excelencia, empleado para medir el nivel de desigualdad en los ingresos entre ciudadanos de un determinado territorio, de modo que altos valores denotan disparidad económica en la sociedad. Un desarrollo económico sostenible debe velar por la mejora de las condiciones económicas y de vida de las poblaciones locales, así como la disminución de los niveles de desigualdad. En ese sentido, es preciso desarrollar alternativas que permitan reducir este valor en el destino. Se estima que pueda estar asociado a la existencia de negocios relacionados con el turismo y otros sectores, que provoca la existencia de una distribución no equitativa o similar de las riquezas.

Mientras tanto, en la dimensión social, al igual que en las restantes (Política y Tecnológica) ningún criterio de los considerados alcanza a llegar al valor deseado de sustentabilidad (Figura 8). Analizando los indicadores ISc2 y el ISc9 el primero de estos es representativo de la preparación de la fuerza de trabajo en el territorio, es decir, se relaciona directamente con el desarrollo profesional y laboral de los empleados en el sector; para lo cuál los residentes permanentes no tienen educación y entrenamiento suficientes y sus expectativas laborales están relacionadas con puestos gerenciales (BARRIGA, 2015); dejando puestos operativos inclusivo con salarios menores a lo establecido por la ley para los residentes temporales o ilegales, en la población se percibe una constante disputa entre residentes locales y los residentes temporales; los primeros culpan a los inmigrantes de los problemas del archipiélago, como por ejemplo la ausencia de una conciencia ambiental, la basura. Dicha situación responde al típico patrón del turismo, donde hay una demanda creciente de bienes y servicios que a la larga deja menos ganancias en la economía local y desplaza a los residentes (BARRIGA, 2015) y que a su vez afectan su sostenibilidad económica.

Por su parte, el porcentaje de hogares con acceso al agua proveniente de red pública (ISc9), que también tiene un valor cercano al establecido como ideal, responde a la calidad de vida de la población local y a la seguridad momentánea en el suministro del agua, sin embargo, se percibe problemas ambientales ligados a la contaminación de las fuentes de agua.

Este problema se agrava, debido a la escasez de agua dulce que es particularmente crítica en Galápagos, dada su condición de hábitat insular, por lo que el aumento de turistas y la migración podría afectar la accesibilidad del suministro que conlleva riesgos para la salud.

Siendo el agua uno de los factores que determinan el bienestar de los turistas, su baja calidad suele estar asociada a la posibilidad de padecimientos de enfermedades, lo cual es un elemento que atenta contra la imagen del destino.

Valores bajos de este indicador pueden constituir un freno en el desarrollo del sector. Se debe tener en cuenta que, en muchas ocasiones, la elección de un destino depende de sus condiciones de salubridad, donde el acceso al agua potable juega un papel primordial. 


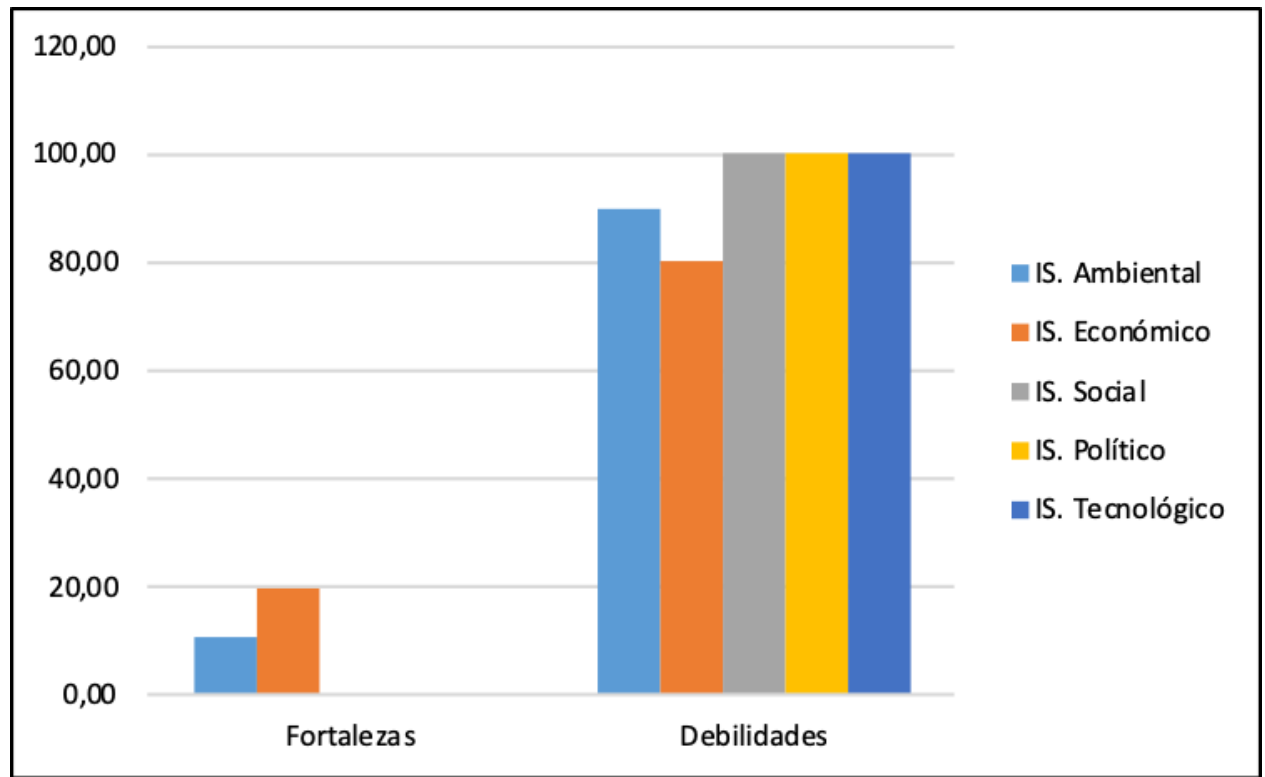

Figura 8: Fortalezas y Debilidades por Dimensión (\%).

Figure 8: Strengths and Weaknesses by Dimension (\%).

Fuente: Elaboración propia. Source: self made.

Existen además otras cuestiones sociales que atentan contra la sustentabilidad del destino en mayor medida, por cuanto tienen valores alejados de las metas establecidas. Todos son negativos. El primero de estos es la relación entre turistas y pobladores locales durante el período de máxima afluencia ( $\left.\mathrm{ISc}_{4}\right)$. Si bien económicamente es necesario que aumente o se mantenga el número de turistas, hasta un valor que afecte de la menor manera posible las condiciones naturales y el entorno, también es deseable que no sea mucho mayor que el número de pobladores, pues podría causar efectos negativos del turismo en la comunidad. Hay un $5 \%$ más de turistas que de pobladores en la etapa de máxima afluencia, contra un valor deseado aproximado de $0 \%$, o de igualdad entre ambos (pobladores y turistas). Este indicador es necesario para establecer objetivos o límites respecto del número de turistas que la comunidad cree poder acoger sin dejar de disfrutar de ventajas óptimas.

Los otros dos indicadores que mayor necesidad de atención presentan son la tasa anual de crecimiento entre los pobladores permanentes de las islas (ISc5) y la tasa de crecimiento anual interesal de la vivienda en Galápagos ( $\mathrm{ISc}_{7}$ ), también negativos y con una elevada relación. El aumento de la población trae consigo aumento en la demanda de viviendas y, por consiguiente, mayor utilización de los espacios y servicios disponibles. Ambos valores están también asociados a las posibilidades de empleo y emprendimiento de la región. Aspectos económicos que influyen directamente en la demografía de una región. En ese sentido, las regulaciones de traslado y vivienda del destino deben ser revisadas en función de lograr no aumentar la diferencia entre los valores ya determinados y los deseados en función de garantizar la sustentabilidad ambiental del destino.

La dimensión política de la sustentabilidad cuenta con nueve indicadores. Solamente dos de ellos son negativos, aunque el $100 \%$ tiene un comportamiento lejano al nivel de aspiración; esto es, falta de sustentabilidad en esta dimensión. Solamente cuatro tienen valores extremos: dos con valor cercano a la situación deseada y dos con valores más alejados que la mayoría. 
Los menos preocupantes son los que están relacionados con el control del cumplimiento de las normativas referentes a los estándares ambientales a las embarcaciones que ingresan $u$ operan en la región $\left(\mathrm{IP}_{6}\right)$ y la renovación de las licencias de pescadores artesanales (PARMA). El primero, está destinado a controlar la calidad de las embarcaciones en el territorio, principalmente con el control de la emisión de gases de efecto invernadero y desechos provocados por las embarcaciones. La segunda busca inspeccionar la actividad de la pesca en el territorio con el ánimo de mantener el control de la biodiversidad marina y su relación con el turismo. La diferencia de ambos indicadores con respecto a la situación actual de sustentabilidad es de solo el $10 \%$.

Las acciones del control de uso de tierra denotan la existencia de gran cantidad de infracciones. El Porcentaje de infracciones detectadas en patrullajes terrestres para el control del uso de la tierra $\left(\mathrm{IP}_{9}\right)$ es elevado (más del $12 \%$ ), por lo que las acciones deben estar encaminadas a garantizar un mayor control sobre este recurso.

En orden de garantizar la realidad de la sustentabilidad turística en el ámbito político, los residentes deben jugar un rol fundamental en el proceso de toma de decisiones (GUNN, 1994; HART, 1998; MURPHY, 1983; PIGRAM, 1990; SIMMONS, 1994). Ya que muchos de los problemas políticos que surgen en el curso de obtener la sustentabilidad turística están asociados con los derechos de los residentes, otros incluyen la ausencia de la colaboración de los implicados o de la comunidad. También, la falta de liderazgo comunitario, escasas regulaciones, el rol de las Organizaciones No Gubernamentales (ONGs), el desplazamiento de los residentes y el control externo sobre los procesos por parte de los inversores extranjeros ( $\mathrm{CHOl}$; SIRAKAYA, 2006).

Finalmente, la dimensión tecnológica cuenta con solo cuatro indicadores. Todos ellos enfocados en la utilización de las TICs por parte de los pobladores y su influencia en el desarrollo turístico de la región. Esta dimensión tiene gran importancia, de acuerdo con las tendencias contemporáneas y la introducción de las Tecnologías de la información y las Comunicaciones en el desarrollo turístico.

En ese sentido, se debe destacar que recientemente Google ha acordado que brindará su apoyo a los miembros de la OMT para hacer frente a las nuevas tendencias digitales y al proceso de transformación que está experimentando el turismo y que el sector necesita acometer para aprovechar al máximo su potencial de desarrollo y su contribución a la sostenibilidad. Las competencias digitales son de vital importancia para la competitividad de un sector como el nuestro, que se caracteriza por el cambio tecnológico y la creación constante de nuevos modelos de negocio (OMT, 2019a).

Por ello la importancia de considerar indicadores de esta índole en le sustentabilidad del destino. Pues si se equipa a los ministerios de turismo con las competencias, herramientas y programas que necesitan para comercializar sus productos en línea con seguridad, haremos crecer las oportunidades de empleo y de generación de ingresos en el sector (OMT, 2019).

A pesar de que aún los indicadores de la dimensión tecnológica no alcanzan los valores deseados de sustentabilidad, existe un elevado número de personas con teléfonos celulares activos, lo que facilita el nivel de comunicación. También tienen un alto valor en cuanto a la cantidad de personas que utilizan la computadora, principalmente en relación con el total nacional. Aun así, esta cuantía necesita ser 
incrementada, con la finalidad de garantizar mayor preparación de la población local y posibilitar, en un futuro, el aumento de la realización de transacciones por medio de la tecnología.

No obstante, menos del $50 \%$ de los turistas planifica su viaje por Internet, cantidad que podría aumentar por las condiciones actuales internacionales del uso de la Internet y las comunicaciones. Adicionalmente, una mayor promoción del destino en las redes sociales podría contribuir a atraer visitantes con un alto grado de afinidad con la naturaleza y un mayor poder adquisitivo. Finalmente, el número de usuarios de Internet por cada 100 habitantes $\left(\mathrm{IT}_{1}\right)$ es el indicador más deprimido de esta dimensión, lo que conlleva también al bajo valor del uso de Internet para la planificación del viaje (IT4). No obstante, se trabaja en la ampliación de las redes de Internet en el destino como parte del plan de inversiones de empresas de comunicaciones del país, además de la creciente importancia de las TICs en el sector.

La creciente utilización de las redes sociales, "big data", inteligencia artificial y análisis predictivos, provee herramientas poderosas para el mejoramiento de la calidad del sector a través de mayor exactitud, visión estratégica y mejor compromiso con el viajero (OMT, 2019b).

\section{Consideraciones Finales}

El turismo es uno de los sectores más importantes de la economía de Galápagos y por ello debería ser una de las actividades económicas que generan menor impacto al ambiente, ya que esta de desarrolla sobre la base de los recursos naturales; el turismo en Galápagos debe desarrollarse dentro del modelo de turismo sostenible minimizando sus impactos y garantizando la sostenibilidad para el futuro, un desarrollo descontrolado ejerce una presión innecesaria sobre los recursos naturales.

Del análisis teórico realizado en esta investigación se encontraron varias herramientas para medir la sustentabilidad turística en la que destacan los indicadores por su capacidad de identificar características que se desean medir, dentro de estas herramientas se encuentran la agregación que es un método adecuado para medir la sustentabilidad turística ya que está avalada, se ajusta plenamente al concepto definido, su aplicación tiene buena aceptación y permiten aprovechar sus ventajas, entre las que sobresale que la medida o indicador compuesto obtenido se ajusta a nivel de análisis territorial y se compone de elementos fácilmente comprensibles por el usuario final. Ello contribuye a garantizar la utilidad de estos instrumentos en la gestión de los destinos turísticos de forma sustentable y la posibilidad de influenciar las decisiones tomadas a interpretar los resultados. Además, la medida puede aplicarse a niveles administrativos que, de forma desagregada, permiten realizar análisis comparativos territoriales o temporales, en caso de tratarse de la gestión de la sustentabilidad turística en un solo territorio.

En conclusión, este enfoque resulta apropiado para crear índices de gestión de la sustentabilidad turística en el destino propuesto por cuanto presenta innumerables ventajas y sus puntos débiles pueden ser salvados mediante el empleo de aproximaciones y una rigurosa selección de los indicadores a emplear y de sus valores correspondientes. 
Como notamos las principales aproximaciones abarcan el aumento del desarrollo económico de las localidades receptoras, la mejora de la calidad de vida de estas y la satisfacción de las expectativas de los visitantes, es así que su aplicación ha dejado de estar centrada a tres dimensiones; incorporando otros factores como los políticos y tecnológicos las cuales se consideran fundamentales dado la importancia de la implementación de políticas para la gestión de los destinos así como incorporar herramientas tecnológicas para minimizar los impactos negativos a los destinos.

Bajo este contexto para la selección de indicadores se utilizó la metodología planteada y mediante la aplicación de pruebas estadística se ha logro identificar una propuesta de un sistema de indicadores plasmados en las dimensiones ambientales, económicos, socioculturales, políticas y tecnológicos para la gestión y medición de la sostenibilidad del destino turístico Galápagos, para los cuáles se aplico varias pruebas estadísticas pudiendo concluir que el conjunto de indicadores seleccionados presenta una elevada consistencia interna; esto es, que miden el concepto por el cual fueron elegidos.

Al evaluar el índice de sustentabilidad y obtener una medida única se encuentran diversidad de procedimientos, de entre los cuales ninguno sobresale como el más acertado; dentro de estos, la Programación por Metas permite incluir diversidad de aspectos de diferente índole, percepciones de los implicados y brinda la posibilidad de agregar toda la información que se disponga, de ahí su notable utilidad y su aplicación permitió realizar un análisis detallado desde el punto de vista dimensional y global de la situación de sustentabilidad, identificando las dimensiones e indicadores con mayor participación en la medida obtenida.

De la propuesta planteada para el monitoreo de la sustentabilidad del destino turístico Galápagos podemos asumir que de acuerdo con los niveles de aspiración establecidos, muestra una situación de sustentabilidad desfavorable, marcada principalmente por los aspectos ambientales, a pesar de ser estos los únicos que presentaron alguna fortaleza en varios de sus indicadores. Este cierto grado de insostenibilidad del destino pone en riesgo la conservación del frágil ecosistema insular; el incremento del número de turistas y la migración trae consigo el ingreso de productos convirtiéndose en una amenaza constante por el riesgo de introducción y dispersión de especies exóticas que pueden en un momento dado interrumpir los procesos evolutivos naturales que originaron la flora y fauna única de Galápagos.

La dimensión económica es la que mas cerca se encuentra de ser un destino económicamente viable, esto debido al auge y a la inyección de dólares que esta actividad ha dejado a residentes y migrantes de Galápagos; sin embargo la distribución de los beneficios no son equitativos gran parte del turismo a bordo se llevan las grandes multinacionales de turismo con sede incluso en otros países; muchos de estos cruceros ni siquiera contratan personal local; ante esta situación el turismo de base local a crecido exponencialmente ofreciendo un tipo de turismo desordenado muchas veces con alojamiento, guianza y otros servicios derivados de la cadena del turismo no autorizados, diversificando de algún modo la mano de obra barata e ilegal y como consecuencia de ello bajando la calidad de los servicios ofertados; además experimentando una mayor presión sobre los recursos naturales, donde se puede evidenciar contaminación por presencia de basura, contaminación de fuentes de agua dulce, sobrecarga de algunos sitios de visita y conflictos sociales entre la población y los turistas; sumado a una consolidada pero débil política de cumplimiento y regulaciones con respecto a la migración y a la operación del turismo 
con base local; la dimensión tecnológica mas bien esta ligada a la cobertura del servicio para optimizar y viabilizar las transacciones sin embargo se debería usar herramientas tecnológica para minimizar el consumo de energía y agua para el sector turismo, por esta razón es importante tomar en cuenta las consideraciones de los valores deseados sobre el índice global y por dimensión para evitar la perdida de la sustentabilidad del destino y sobre todos impactos ambientales; para lo cuál es preciso encaminar estrategias claras de sinergia entre las dimensiones para alcanzar las metas propuestas del tan ansiado turismo sostenible.

A pesar de que ninguno de los indicadores dimensionales consigue obtener el nivel deseado para el destino, los resultados muestran a la dimensión política como la de mejor comportamiento, esto debido a la consolidada política ambiental de las islas, pero que no esta siendo aplicada rigurosamente, por lo que las actuales medidas deben estar encaminadas a mejorar de los valores de estos indicadores.

En este sentido se recomienda una planificación y gestión adecuada orientada a cumplir con los objetivos de sustentabilidad establecidos para el desarrollo del destino y así evitar el deterioro en la calidad de vida de los residentes de Galápagos, la pérdida de la biodiversidad, los impactos económicos negativos y la degradación de los recursos naturales.

En la aplicación se debe lograr una mayor integración de cada una de las dimensiones con el fin de que puedan fluir en armonía sin que ninguna de ellas refleje un mayor grado de sostenibilidad, por lo tanto, la inclusión de cuestiones subjetivas se hace necesaria en estudios futuros en el destino, así como el incremento de criterios ambientales para su análisis, los gestores de turismo deben implementar mecanismos capaces de prever los impactos ambientales, sociales, políticos y tecnológicos y ofrecer nuevas alternativas de acción y complementar los indicadores seleccionados para cada dimensión de acuerdo a nuevas lecturas y análisis que agreguen nuevas orientaciones para los indicadores de sustentabilidad del turismo, incluyendo la indicación de procedimientos de medición y la forma de aplicación de los indicadores, propiciando un análisis más amplio y coherente de la sustentabilidad del desarrollo turístico.

\section{Referencias}

ACEVEDO-GUTIÉRREZ, A.; ACEVEDO, L.; BOREN, L. Effects of the presence of official-looking volunteers on harassment of New Zealand fur seals. Conservation Biology, v.25, n. 3, p. 623-627, 2011.

ÁLVAREZ DÍAZ, R.; VALDÉS PELÁEZ, L. Selección e indicadores para la evaluación del desarrollo sostenible de un destino turístico. Aplicación al municipio de Gijón. ROTUR, Revista de Ocio y Turismo, v.11, p. 12-21, 2016.

ANTONINI, A. La medida de la sostenibilidad de la ciudad histórico-turística. 2009. 492 f. (Tesis doctoral) - Cátedra UNESCO de Sostenibilitat, Universitat Politécnica de Catalunya.

BARRIGA, A. M. La contradicción del turismo en la conservación y el desarrollo en Galápagos-Ecuador. Estudios y perspectivas en turismo, v.24, n. 2, p. 399-413, 2015.

BROWLIG, S.; GIBBON, P. Counting Carbon in the Marketplace: Part I - Overview Paper. Paris. 2009. 
CHOI, H. C.; SIRAKAYA, E. Sustainability indicators for managing community tourism. Tourism Management, v.27, p. 1274-1289, 2006.

COM. Methodological work en measuring the sustainable development of tourism. Part 2: Manual on sustainable development indicators of tourism. Office for Official Publications of the European Communities, p. 26. 2006.

COSTA, C. C.; OLIVEIRA, I. S. S.; GOMES, L. J. Percepción ambiental como estrategia para el ecoturismo en unidades de conservación. Estudios y perspectivas en turismo, v.19, n. 6, p. 1105-1120, 2010.

CUNHA, A. A. Negative effects of tourism in a Brazilian Atlantic forest national park. Journal for Nature Conservation, 18, n. 4, p. 291-295, 2010.

DAVIDSON, D. J. The Applicability of the Concept of Resilience to Social Systems: Some Sources of Optimism and Nagging Doubts. Society and Natural Resources, v.23, n. 12, p. 1135-1349, 2010.

DE GALÁPAGOS, O. d. T. Boletín Observatorio de Turístico-2014. 2014.

DE OLIVEIRA ARRUDA, D.; PASQUOTTO MARIANI, M. A.; MORALES DE QUEIROZ CALEMAN, S. Coordinación y estructuras de gobernanza en un sistema productivo de turismo. Estudios y perspectivas en turismo, 23, n. 2, p. 343-361, 2014.

DÍAZ, G.; NORMAN, A. Manual de Procedimientos para Entrenadores en Turismo Sustentable. 2006. $122 \mathrm{p}$.

DOMÍNGUEZ SERRANO, M.; BLANCAS PERAL, F. J.; GUERRERO CASAS, F. M.; GONZÁLEZ LOZANO, M. Una revisión crítica para la construcción de indicadores sintéticos. Revista de Métodos Cuantitativos para la economía y la empresa, v.11, p. 41-70, 2011.

FERNÁNDEZ, M. C. P.; FERNÁNDEZ, J. I. P. ¿ Existe gobernanza en la actual gestión de los destinos turísticos?: Estudio de casos. Pasos: Revista de turismo y patrimonio cultural, v.12, n. 4, p. 685-705, 2014.

GRENIER, C. Culturas isleñas. INFORME GALÁPAGOS 2011-2012, p. 31, 2012.

GUNN, C. A. Tourism planning: basics, concepts, cases. Washington DC: Taylor \& Frances, 1994. (3rd ed.

HART, M. Indicators of sustainability. 1998. Disponível em: http://www.subjectmatters.com.

HERNANDEZ, A. M. S.; DA SILVA, E. V.; SANCHEZ, M. A. F. Turismo Sustentable y los diferentes enfoques, aproximaciones y herramientas para su medición. PASOS Revista de Turismo y Patrimonio Cultural, v.17, n. 5, p. 901-914, 2019.

HIGHAM; SHELTON. Tourism and wildlife habituation: Reduced population fitness or cessation of impact? Tourism Management, 32, n. 6, p. 1290-1298, 2011.

INSKEEP, E. L. Tourism planning: an integrated and sustainable development approach. Van Nostrand Reinhold, New York. 1991.

KOCIOLEK; A.P., C.; CLAIR, S.; S., P. D. Effects of road networks on bird populations. Conservation Biology, v.25, n. 2, p. 241-249, 2011. 
LOZANO-OYOLA, M.; BLANCAS, F. J.; GONZÁLEZ, M.; CABALLERO, R. Sustainable tourism indicators as planning tools in cultural destinations. Ecological Indicators, v.18, p. 659-675, 2012.

MACÁRIO DE OLIVEIRA, V.; PASA GÓMEZ, C. Indicadores de sustentabilidad para la actividad turística. Una propuesta de monitoreo usando criterios de análisis. Estudios y Perspectivas en Turismo, v.22, p. 177-197, 2013.

MAYER, A. L. Strengths and weaknesses of common sustainability indices for multidimensional systems. Environmental International, v.34, p. 277-291, 2008.

MILLER, G. The development of indicators for sustainable tourism: results of a Delphi survey of tourism researchers. Tourism Management. v.22, p. 351-362, 2001.

MUNDA, G. Social Multi-Criteria evaluation for a sustainable economy. SpringerVelgrado, 2008.

MURPHY, P. E. Perceptions \& attitudes of decisionmaking groups in tourism centers. Journal of Travel Research, v.21, p. 8-12, 1983.

NELSON, F. Community rights, conservation and contested land: The politics of natural resource governance in Africa. Earthscan, London, p.342. 2010.

OMT. Desarrollo turístico sostenible. Guía para los planificadores locales. Madrid: 1997.

OMT. Climate Change and Tourism. Responding to Global Challenges. World Tourism Organization, Madrid, Spain: World Tourism Organization and the United Nations Environment Programme, 2005. 978-92-844-1234-1.

OMT. Comunicado de prensa PR No. 19019. Madrid, España, 2019a. Disponível em: http://www2.unwto.org/press-release/2019-03-07/google-partners-unwto-digitalskills-development.

OMT. High- level Dialogue on Digital Skills in Tourism. 2019b. Disponível em: http://europe.unwto.org/event/high-level-dialogue-digital-skills-tourism.

OMT; PNUMA. Por un turismo más sostenible. Guía para responsables políticos. Organización Mundial del Turismo, 2006. 238 p. (Programa de las Naciones Unidas para el Medio Ambiente. 13: 978-92-844-1189-4.

ORGANIZATION, W. T. Indicators of sustainable development for tourism destinations: a guidebook. 2004. 9284407265.

PERAL, F. J. B.; LOZANO, M. G.; CASAS, F. M. G.; OYOLA, M. L. Indicadores sintéticos de turismo sostenible: una aplicación para los destinos turísticos de Andalucía. Rect@: Revista Electrónica de Comunicaciones y Trabajos de ASEPUMA, n. 11, p. 85-118, 2010.

PÉREZ, V.; HERNÁNDEZ, A.; GUERRERO, F.; LEÓN, M. A. et al. Measuring the sustainability of Cuban tourism destinations considering stakeholders' perceptions. International Journal of Tourism Research, v.19, p. 318-328, 2017.

PÉREZ-LEÓN, V. E.; CANIVELL-CRUZ, G. The use of sustainability indicators as tools in tourist destination management.

PERSHA, L.; AGRAWAL, A.; CHHATRE, A. Social and ecological synergy. Science, v.331, p. 1606-1608, 2011. 
PIGRAM, J. J. Sustainable tourism—policy considerations. Tourism Studies, v.1, n. 2, p. 2-9, 1990.

PINTÉR, L.; HARDI, P.; BARTELMUS, P. Sustainable Development Indicators. Proposals for a Way Forward. In: Discussion Paper Prepared for the United Nations Division for Sustainable Development (UN-DSD), 2005, International Institute for Sustainable Development p. 42.

PIRES, P. d. S.; PHILLIPI JR, A.; RUSCHMANN, D. Turismo e meio ambiente: relação de interdependência.In: Gestão ambiental e sustentabilidade no turismo, 2010.

PULIDO FERNÁNDEZ, M. d. I. C. Metodología para la implantación de la gobernanza como herramienta de gestión de destinos turísticos. 2014. 501 f. (Tesis doctoral) - Departamento de Economía, Facultad de Ciencias Sociales y Jurídicas, Universidad de Jaén.

REED, S.; FRASTER, E.; DOUGILL, A. An adaptive learning process for developing and applying sustainability indicators with local communities. Ecological Economics, v.59, p. 406-418, 2006.

SALINAS, E.; LA O, J. A. Turismo y sustentabilidad: de la teoría a la práctica en Cuba. Cuadernos de Turismo, Universidad de Murcia, v.17, p. 201-221, 2006.

SANCHS, J. The Age of Sustainable Development. Press. New York. 2015.

SILVA COELHO, J. A. Un Índice de Desarrollo Turístico basado en el Ciclo de Vida de un Destino. 2010. 510 f. - Departamento de Dirección de Empresas y Sociología, Facultad de Ciencias Económicas y Empresariales, Universidad de Extremadura.

SIMMONS, D. G. Community participation in tourism planning. Tourism Management, v.15, n. 2, p. 98-108, 1994.

TORRES, T.; SALA RÍOS, M.; FARRÉ PERDIGUER, M. Grado de sostenibilidad de los ámbitos turísticos catalanes. PASOS. Revista de Turismo y Patrimonio Cultural. Special Issue, v.13, n. 6, p. 208, 2015.

UNWTO. International tourist arrivals up 4\% and reach a record 1.2 billion in 2015. UNWTO Word Tourism Barometer, v.14, p. 1-6, 2016.

WITTEMEYER, G.; ELSEN, P.; BEAN, W. T.; BURTON, A. C. O. et al. Acceleratedhumanpopulation growth at protected area edges. Science, v.321, p. 123-126, 2008.

YURI HANAI, F. Sistema de indicadores de sustentabilidade: uma aplicação ao contexto de desenvolvimento do turismo na região de Bueno Brandão, Estado de Minas Gerais, Brasil. 2009. 432 f. (Tese apresentada à Escola de Engenharia de São Carlos (EESC) da Universidade de São Paulo (USP) para obtenção do título de Doutor em Ciências da Engenharia Ambiental) - Escola de Engenharia de São Carlos, Universidad de São Paulo, São Carlos, Estado de São Paulo.

ZSÖGÖN, S. Antropología Ambiental: Conflictos por recursos naturculturales y vulnerabilidad de poblaciones. Madrid. 2014. 
Angelica Maria Saeteros: Universidade Federal do Ceará, Fortaleza, CE, Brasil. E-mail: angelicasaeteros@yahoo.com

Link para o currículo Lattes: http://lattes.cnpq.br/0191372904131328

Edson Vicente da Silva: Universidade Federal do Ceará, Fortaleza, CE, Brasil. E-mail: cacauceara@gmail.com

Link para o currículo Lattes: http://lattes.cnpq.br/3354228537186786

Diego Paul Viteri Nuñez: Universidad Estatal de Bolivar, Guaranda, Bolivar, Ecuador.

E-mail: diegoviteri@yahoo.de

Link para o currículo Lattes: http://lattes.cnpq.br/4405024363565371

Data de submissão: 28 de fevereiro de 2020.

Data de recebimento de correções: 12 de junho de 2020

Data do aceite: 12 de junho de 2020

Avaliado anonimamente 